\title{
COMPARATIVE ECOPHYSIOLOGICAL STUDY OF THE SEASONALLY DEPENDENT NON-STRUCTURAL CARBOHYDRATE POOL OF THE FRUCTAN-ACCUMULATING HELIANTHUS TUBEROSUS, CICHORIUM INTYBUS AND DACTYLIS GLOMERATA
}

\author{
Marianna Marschall*, Szidónia Sütő \& Szidónia Szőke \\ Eszterházy Károly University, Institute of Biology, Department of Botany and Plant \\ Physiology, 3300 Eger, Leányka str. 6, Hungary; \\ *E-mail: marschall.marianna@uni-eszterhazy.hu
}

\begin{abstract}
Our experimental results show that fructans play a major role in the physiological processes of the three species. The two species (Helianthus tuberosus, Cichorium intybus) belonging to the Asteraceae tend to accumulate low molecular weight oligosaccharides and the species (Dactylis glomerata) belonging to the Poaceae accumulates medium and high molecular weight oligo- and polysaccharides to increase physiological performance, stress tolerance. Taking into account the climatic and weather conditions, we concluded that the fructan production of the plants belonging to the Asteraceae investigated in North Hungary is mainly influenced by the cold, while the species belonging to the Poaceae is influenced by temperature factors and also the amount of precipitation.
\end{abstract}

Keywords: non-structural carbohydrates, fructans, seasonality, Helianthus tuberosus, Cichorium intybus, Dactylis glomerata

\section{INTRODUCTION}

In addition to starch and sucrose, the main products of photosynthesis, a third type of short- and long-term carbohydrate and energy storage component, fructan, is produced in a small fraction (15\%) of the flora (Van der Meer et al. 1994). Fructans have been researched for over 210 years. In 1993, Suzuki and Chatterton published a complete book on the subject. Fructans were isolated not only from higher plants, but also from bryophytes (Maas and Craigie 1964, Sulieman et al. 1979, Marschall 1998, Marschall 2010) and from a number of fungi, algae and bacteria (Lewis 1984). Plant carbohydrates can be divided into two groups 
based on their function: structural and non-structural carbohydrates (NSC). The former includes cell wall constituents such as cellulose, pectin, etc., while the latter includes components involved in metabolic processes such as glucose, starch and fructans. Non-structural carbohydrates are the primary products of photosynthesis, key regulators of adaptation to environmental stress, and provide substrates for growth and metabolism, and thus a plant's NSC level provides an important indicator of its carbon source and sink capacity (Liu et al. 2018). The role of fructans as storage carbohydrates and their function in desiccation tolerance and low temperature stress is well emphasized in higher plants (Marschall 2010). Fructans also act as antioxidants, scavenging reactive oxygen species and preventing cell damage under abiotic stress conditions (Peshev et al. 2013). Fructans are water-soluble carbohydrate chains that are usually formed by the attachment of several fructose units (a few hundred or even thousands) to a glucose unit on a single end-chain sucrose molecule (Chatterton et al. 2006), but this terminal and the glucose unit may also be missing. In each case, their basic unit is a trisaccharide monomer consisting of a glucose and 2 fructose molecules in 3 possible modes of linking (G-F-F in two ways, F-G-F). There are three main types of fructans: linear inulins containing mainly $\beta(2-1)$ bonds, e.g. 1-kestose, levans (or fleins) containing $\beta$ (2-6) bonds, e.g. 6kestose and the graminans containing branched bonds e.g. kestopentaose 6,6 \& 1 (Van den Ende et al. 2011) and studies have reported two other major groups, the inulin neoseries and the levan neoseries (Vijn and Smeekens 1999). In the latter, glucose is not located terminally but within the molecule and is bound to the fructoses at sites 2-1 and 2-6. Their economic importance is that they improve the quality of forage crops and are suitable for human consumption.

About $15 \%$ of the Angiosperms, about 45,000 species, are capable of synthesizing fructans, fructose-based oligo- and sucrosebased polysaccharides (Van den Ende et al. 2011). The most studied species come from the order of the Asterales, the Poales, the Liliaes, the Dipsacales and the Boraginales (Van den Ende et al. 2011). The plant part in which fructan accumulates (root, tuber, stem, leaf) is a characteristic feature of the order (Van der Meer et al. 1994). Fructans are stored in wheat and barley in stems and leaves, tulips and onions in their onions, and in the root/tuber of 
chicory and Jerusalem artichoke. They can accumulate up to 20$50 \%$ of the dry weight in the above mentioned different plant parts, but their content can even reach $70 \%$ of the dry weight in bulbs (Marschall 2010). Fructan-rich species accumulate only traces $(\sim 1 \%)$ of starch. This also proves that fructan is a real alternative to starch. At cellular level, fructans accumulate in the vacuole (Wagner and Wiemken 1986), where they play an important role in turgor regulation (Pontis 1989), and because of the size of the vacuole is relatively large compared to other cellular organelles, it allows accumulation of high concentrations of fructan (de Moraes et al. 2016). More molecules mean that these cells are more resistant to osmotic pressure or even cold, so these plants are better adapted to sudden climate changes. The size of fructan polymers can be altered quickly; this could be an explanation for their role in osmotic adjustment. Polimerization or breakdown of fructan will alter vacuolar osmotic potential, and hence may alter turgor pressure (Marschall 2010). The DP (degree of polymerization) appears to closely track changes in the external environment.

Fructans were later also discovered in the apoplast (Livingston and Hanson 1998, Van den Ende et al. 2005). To explain this, it has been hypothesized that fructan molecules are transported to the outside of the plasma membrane by exocytosis via vesicles (Valluru and Van den Ende 2008). Cytoskeletal microtubules, which have a wide variety of functions, are very sensitive to temperature drop, which can cause their depolymerization (Kerr and Carter 1990). It is likely that fructans protect plants from various environmental stresses such as frost and drought (Valluru and Van den Ende 2008) by stabilizing membranes. It was found that fructans inserted between the headgroups of different kinds of phospholipids with some preference for phosphatidylethanolamine (Vereyken et al. 2001, Hincha et al. 2002, 2003). Pollock's (1986) study shows that starch synthesis decreases dramatically when the temperature drops below $10^{\circ} \mathrm{C}$, but photosynthetic processes and fructan production are much less sensitive to low temperatures, suggesting that fructan production benefits those plants that actively photosynthesize during the winter and early spring. The protection of the photosynthetic apparatus as temperature rises, and mobilization of carbohydrates stored in fructans for rapid growth are strong influencing factors in the evolution of fructan 
production (Vijn and Smeekens 1999). As well as being the main storage carbohydrate, vacuolar fructans with their synthesis can regulate the concentration of sucrose in plant cells, thereby preventing the inhibition of photosynthetic sugar-induced feedback (Pollock 1986). Global distribution shows that the temperate climate is particularly rich in fructan-producing plants, whereas in the tropical regions they are virtually absent (Hendry and Wallace 1993). Drought, high irradiance or/and low temperature favours fructan accumulation in Angiosperms, so their relevance is linked to desiccation and freezing resistance or emphasized in response to cold and dry seasons (Marschall 2010).

Plant fructans may differ in their molecular structure and weight, in the degree of polymerization (DP), and in the coupling pattern between fructosyl groups (Abeynayake et al. 2015). The degree of polymerization (DP) is determined by the number of glucose-fructose units. Fructan oligosaccharides are typically characterized by DP $<10$. Inulin-type chains are generally between DP 2-60 (Sissons and Fellows 2014), while levan types are slightly longer (DP <200) (Avigad and Dey 1997). These values vary with the current weather conditions and the physiological requirements of the plant. Low polymerization, short oligosaccharides belong to the low molecular weight group (LMW), and long polysaccharides belong to the high molecular weight group (HMW). The simplest, inulin-type fructans occur mostly in dicotyledons, while the levan and graminan types occur in monocotyledons (Van den Ende et al. 2011). Although there are many different structural forms of fructans, their appearance in each species is species-specific, ranging from simple inulin homologous in Jerusalem artichoke tubers to complex branched bonds in the leaves of grasses (Cairns and Ashton 1993). A study of Cairns and Ashton (1993) reveals that this species specificity does not depend on the particular plant tissue/cell but on the enzymes that synthesize it in the species.

One enzyme responsible for the synthesis of inulin-type fructan molecules is fructan: fructan fructosyltransferase (FFT), F-type (uses fructose as a donor) fructosyltransferase (FT), and another enzyme which is S-type (uses sucrose as a donor) FT (Van den Ende et al. 2011), sucrose: sucrose fructosyltransferase (SST), which binds a $\beta$-D-fructose moiety of a sucrose to another Dglucose moiety of sucrose, a trisaccharide, kestose (GFF), and then added further fructose units in the chain extension process 
(Marschall et al. 1998). Generally, a primary sucrose acts as a fructose acceptor at the start of chain extension, leaving a glucose moiety at one end of the polymer (Franken et al. 2013). Whereas in monocotyledons, where the other two fructan types occur, a much more complex mixture of FTs is required, depending on the species (Yoshida et al. 2007).

\section{Changes in plant fructan content to various environmental influences}

Depending on environmental conditions and plant ontogeny, fructans may be stored where they are synthesized or at their site of use (Van der Meer et al. 1994). The accumulation and reduction of fructans in plants is mainly dependent on the temperature, i.e. the season and the amount of precipitation. Chatterton and coworkers (1989) found that in grasses growing in cold seasons, in addition to being a reserve carbohydrate, fructans accumulate in the vacuole, allowing photosynthesis to continue at low temperatures when other carbohydrate reserves would saturate it. Puebla and coworkers (1997) compared the fructan production of two Bromus species (Poaceae) in the context of temperature and precipitation differences. Cold-adapted species synthesized fructan permanently, whereas species adapted to warmer climates accumulated it only under cold stress. In a study by Pollock and Jones (1979) fructan levels and mean molecular weights were measured throughout the year in leaves and stems of four forage grasses (Poaceae). In contrast to other studies, the major period of fructan synthesis in all varieties was autumn and winter, with maximal values in December. Extensive hydrolysis, accompanied by a decline in mean molecular weight, occurred between January and April. Fructan accumulation was maximal in periods when growth was limited. In low temperature wheat (Triticum aestivum), as the carbohydrate is produced in excess, the plant stores fructan in the stem (Bancal and Triboi 1993). Ernst and coworkers (1996) concluded that the inulin reserves of Asteraceae species were highest in the autumn months before the plants start to break it down due to the low temperature. In the case of woody plants, the exact opposite is true, at least in a study by Furze and coworkers (2019). Their research, which included deciduous and evergreen species, reveals that the amount of non-structural carbohydrates (including fructans) was highest during the growth period. Liu and 
coworkers (2018) experimented with 20 evergreen woody plants derived from a subtropical monsoon evergreen forest. They found that starch and NSC concentrations were higher in the dry season in that region, while soluble sugar concentration and the sugar/starch ratio were higher in the wet season. Several studies have been carried out with transgenic plants that otherwise do not produce fructans (Van der Meer et al. 1994, Pilon-Smits et al. 1995, Pilon-Smits et al. 1999, Li et al. 2007, Kawakami et al. 2008). Kawakami and coworkers (2008) introduced the genes of two fructan synthase enzymes into the genome of a frost-sensitive rice (Oryza sativa L.) and concluded that the plant became more resistant to cold after producing fructan molecules.

The aim of this paper is 1) to compare the non-structural carbohydrate pool and its alterations of the fructan-accumulating Helianthus tuberosus, Cichorium intybus and Dactylis glomerata depending on sesonality; 2) to investigate the ratio of high and low molecular weight of fructans of plant organs exposed to stress (temperature and precipitation changes) as a function of seasonality; 3) to obtain new information about the physiological role of soluble carbohydrates, especially fructans in Angiosperms, and their metabolism under various environmental conditions.

\section{MATERIALS AND METHODS}

\section{Plant material}

Helianthus tuberosus L., or Jerusalem artichoke, is a 1.5-3 m high, invasive, aggressive species that survives on many soils due to its broad tolerance. Tubers are also suitable for human consumption and contain inulin-type of fructan, which consists of $\beta$-D-fructosyl units. It is a popular model plant for fructan researchers. In most cases, tubers of the plant have been used for these studies, but similar regulatory mechanisms exist in the stem, although the accumulation of high-polymerisation fructans in tubers is faster (Soja et al. 1989). The inulin content and degree of polymerization depend on the variety, the growth conditions, the time of harvest and the maturity of the tubers (Bach et al. 2015). Soja and coworkers (1989) also found that, before flowering, the stem is the potential fructan storage organ, and after flowering (at the end of autumn), carbohydrates as sucrose units are translocated into tubers. 
Jerusalem artichoke plants used for the experiments were collected in Füzesabony, from a constantly maintained garden in 2018 and 2019 in three seasons, summer, autumn and winter. Laboratory measurements were carried out on tubers only.

Cichorium intybus L. is an $80-100 \mathrm{~cm}$ tall native species of Hungary. It belongs to the Asteraceae family, like the Jerusalem artichoke, and it also contains inulin-type of fructans (Bonnett et al. 1994). It is also a frequently used species in studying fructanmetabolism. The leaves of chicory contain low concentrations of fructans which are most abundant in the basal region of the petiole (Ernst et al. 1995). Concentration of fructans with a high degree of polymerisation (DP) increased significantly during the JulySeptember period, and a decrease of the glucose concentration was found at the same time (Van den Ende et al. 1996). In early October, important changes occurred over a very short period. Concentration of fructans with a low degree of polymerisation (DP) increased in parallel with a significant increase in fructose and sucrose concentrations, but the number of fructans with a high DP decreased. Cichory used for the experiments was collected from the EKU Almagyar Campus in Eger, in 2018 and 2019 in three seasons, summer, autumn and spring. Laboratory measurements were carried out on the root of the plant only.

Dactylis glomerata L. is a $60-120 \mathrm{~cm}$ high, monocot perennial grass that is native to Hungary. There is another type of fructan in the leaves and stems of the plant, levan. The longest fructan chain $(\mathrm{DP}=314$ ) described in Dactylis glomerata (Yamamoto and Mino 1985). This carbohydrate consists of linear (2-6) linked $\beta$-Dfructosyl units and is also found in other grasses (Bonnett et al. 1997). Other species from the Poaceae such as wheat (Triticum aestivum), barley (Hordeum vulgare), and rye (Secale cereale) are also widely used as model plants in fructan research. They are also capable of synthesizing Graminin-type fructans. Volaire and coworkers (1998) reported that the reason why Dactylis can survive extreme drought, even in Mediterranean areas, is related to the plant's high content of fructans with a high degree of polymerization. Sanada and coworkers (2007) in a comprehensive European survey measured the soluble carbohydrate and fructan content of the plant. They concluded that the highest fructan concentrations in Central Europe occured in autumn, which was also due to the fact that the plant was preparing for the winter cold. 
Then, by the beginning of the growing season, when the plant had to mobilize its carbohydrate reserves, fructan concentration had declined as the plant produced new shoots and leaves and was ready to flower. Dactylis glomerata used for the experiments was collected from the EKU Almagyar Campus in Eger, in two seasons, in the summer of 2018 and in the spring of 2019. Stems, internodes and leaves of the plant were used in laboratory measurements. The fructan content was generally the highest in the nodules. The plant materials of the 3 fructan-accumulating Angiosperms (Helianthus tuberosus, Cichorium intybus and Dactylis glomerata) were collected on the same day of the season, e.g. summer, winter and spring (August, February, April), and within 1 month in autumn (OctoberNovember). What was important for the experiment was the weather conditions that characterized the sampling and presampling periods.

\section{Preparation of plant extracts}

Samples for carbohydrate analysis were taken in the middle of the photoperiod. Plant tissue was extracted with $80 \%$ ethanol followed by hot water (Marschall et al. 1998). Supernatant and sediment extracts were also used for assays. 0.5/0.1 g of fresh plant tissue (root, tuber, stem, leaves) was homogenized with $2 \mathrm{ml}$ of $80 \%$ ethanol, then was centrifugated for 10 minutes (10.000G). To the sediment remaining in the tube $1 \mathrm{ml}$ of hot distilled water was added for further extraction and after shaking it was incubated at $70^{\circ} \mathrm{C}$ for 2 hours. During incubation time, the sample was shaken every 30 minutes. Then the tube was centrifuged for 10 minutes at 10.000G and the supernatant (= sediment extract) was kept for assays. Supernatants and sediment extracts were used for fructan, total soluble carbohydrate assay, osmotic potential measurement and thin layer chromatography.

\section{Determination of total soluble sugar and fructan content, and osmotic potential}

Total soluble sugars were detected in plant extracts by the Dubois method (1956). Fructans were quantified using a ketose-specific method with resorcinol (Farrar 1993, Marschall et al. 1998). Extracts were deionised with a mixed bed of Dowex2-1 and Dowex2-50 ion exchange resins before TLC. Fructans were separated by TLC on silica gel plates (Cairns and Pollock 1988) and 
detected with urea-phosphoric acid stain (Wise et al. 1995). Plant extracts $(50 \mu \mathrm{l})$ were used for osmotic potential determination with a freezing point osmometer (OSMOMAT 010). Values are expressed in MPa according to Bajji et al. 2001.

\section{RESULTS}

The soluble carbohydrate content of the Jerusalem artichoke tuber, which also includes fructans, was high in summer due to the high metabolic activity (Figure 1). The plant saved its excess carbohydrate reserves during the spring/summer period so that it could be mobilized from here to the above-ground parts with the onset of cold. This is also evidenced by the high content of the high molecular weight of non-structural sugars, $16100 \mu \mathrm{M} \mathrm{g-1}$ d.w., which represents $60 \%$ of the total amount. By the end of fall, the total soluble carbohydrate content decreased to about one-fifth. This can be explained by the fact that the plant redistributed the energy reserves from the tubers to the stems and leaves, further operating the photosynthetic apparatus at low temperatures and low hours of sunshine. Content of high molecular weight (HMW) sugars was reduced to $30 \%$ of the total amount, and at the expense of long molecule chain degradation, the resulting mono- and oligosaccharides entered the metabolic pathways. In line with this, the proportion of the low molecular weight carbohydrates (LMW) increased from $40 \%$ to $70 \%$ in summer, proving the previous statement. By the end of the winter, the total soluble carbohydrate content began to increase compared to the previous season. This is because, as spring approached, the plant slowly began to accumulate carbohydrates in the tuber again. This finding also explains that LMW carbohydrate levels increased by nearly $75 \%$ during the 4 months between the two samplings. However, HMW was further reduced to $10 \%$, therefore almost all carbohydrates were present in LMW sugars. 


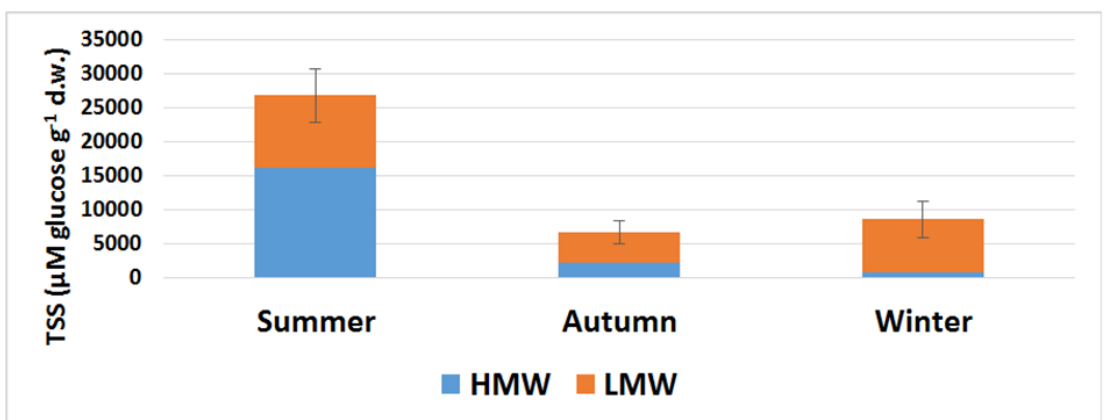

Figure 1. Total soluble sugar content ( $\mu \mathrm{M}$ glucose $\mathrm{g}^{-1} \mathrm{~d}$.w.) of Helianthus tuberosus tuber depending on seasonality. HMW (blue column): high molecular weight of soluble carbohydrates; LMW (orange column): low molecular weight of soluble carbohydrates; Error bars are STDs, which concern the sum of HMW + LMW fructans (total fructan), where $n=5$.

The total fructan content of $H$. tuberosus in summer (in August) was low (Figure 2), consistent with the results of Ernst et al. 1996 and De Carvalho et al. 1997. So, most of the carbohydrates were present in other types of sugars in the tuber. The content of HMW fructans were higher than LMW's, with a ratio of 58: 42\%. This means that the plant stored other sugar molecules rather than fructans. In autumn, even if the fructan content of the tubers was reduced to a minimum, but also the HMW: LMW ratio of its, the plant started to use fructans in metabolic processes as the temperature decreased. This is consistent with the change in HMW: LMW ratio of total soluble carbohydrates over the same period. In winter there was a significant change in the values, the amount of fructan oligosaccharides being extremely high. Because of the frosty soil and low temperatures, the plant had accumulated enormous amounts of fructan molecules by the end of winter. This finding is consistent with the hypothesis of Dias-Tagliacozzo et al. 1999, that $V$. herbacea (Asteraceae), which they investigated, began to intensively transfer its unused photo-assimilates from aboveground organs to its roots as a result of low temperatures. What is striking is that the amount of HMW was less than $1 \%$, so the plant actively used HMW fructans in its metabolism. 


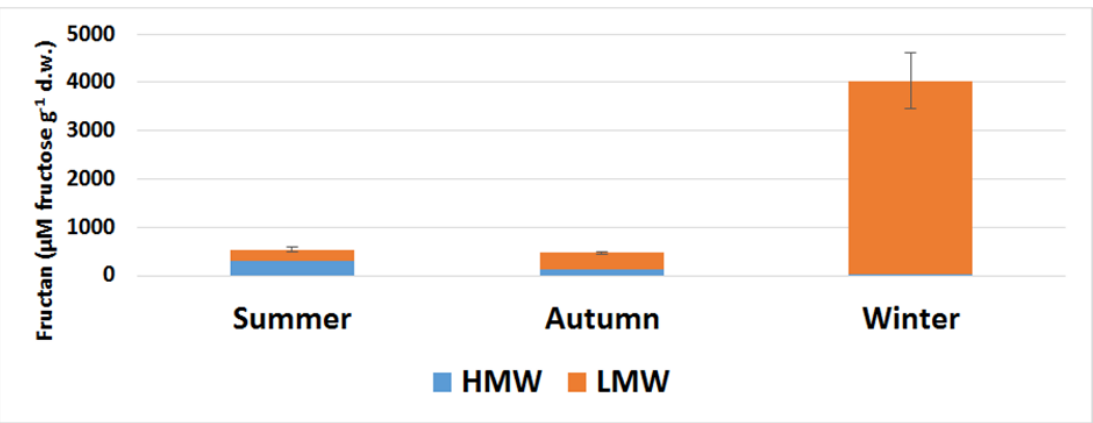

Figure 2. Fructan content ( $\mu \mathrm{M}$ fructose $\mathrm{g}^{-1}$ d.w.) of Helianthus tuberosus tuber depending on seasonality. HMW (blue column): high molecular weight of fructans; LMW (orange column): low molecular weight of fructans; Error bars are STDs, which concern the sum of HMW + LMW fructans (total fructan), where $n=5$.

In summer fructans were found (Figure 2) to be $540 \mu \mathrm{M} \mathrm{g}^{-1} \mathrm{~d} . \mathrm{w}$. of the total soluble carbohydrate content of $26600 \mu \mathrm{M} \mathrm{g}^{-1}$ d.w. (Figure 1), barely $2 \%$. In the autumn, this distribution changed, with fructan molecules accounting for almost one tenth of the soluble carbohydrates. This result also demonstrates that, in colder weather, the Jerusalem artichoke started intensive fructan synthesis. In winter, there was a radical change in the total soluble sugar: total fructan distribution. The proportion of fructans increased to nearly $50 \%$. From this result, it is clear that this species switched from synthesizing other sugars to fructan accumulation under stress (Figure 3).
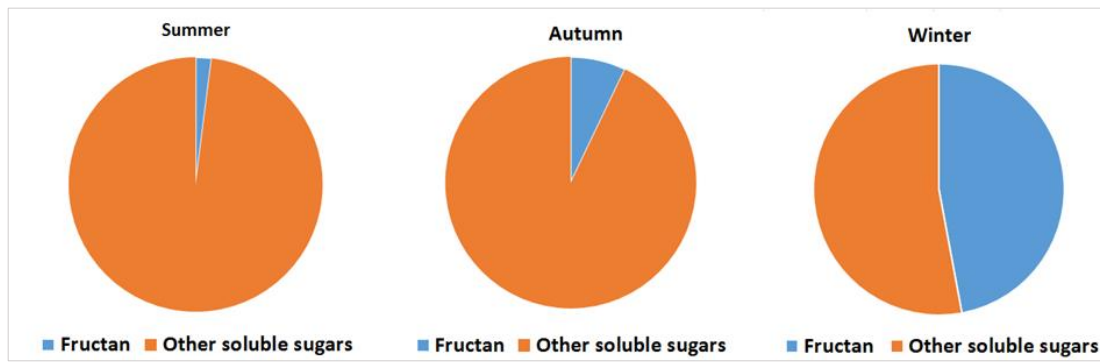

Figure 3. The ratio of fructan (blue) to other soluble carbohydrates (orange) in Helianthus tuberosus tuber depending on seasonality. The plant had total soluble carbohydrate reserves of about $26750 \mu \mathrm{M} \mathrm{g}^{-1} \mathrm{~d}$.w. in summer, $6613 \mu \mathrm{M} \mathrm{g}^{-1} \mathrm{~d}$.w. in autumn and $8571 \mu \mathrm{M} \mathrm{g}^{-1} \mathrm{~d} . w$. in winter.

The soluble carbohydrate content (TSS) of the root of Chicorium intybus was low in summer (Figure 4). This is in line with Limami 
and Fiala's (1993) results measured in France. The value is due to the fact that during the growth period (March-August), the plant devoted its carbohydrate reserves to the development of the aboveground organs, mainly the leaves, the flowers and the crop, and there were no significant physiological processes in the root. The HMW: LMW ratio was 38: $62 \%$. During the summer period, there there was a small amount of high molecular weight soluble carbohydrates in the root of the plant, but a significant change occurred in the subsequent period. In the autumn the TSS content of the root increased significantly, its value increased sixfold. A similar result was obtained by the two researchers mentioned above, although they did not observe the same degree of change. Due to the low temperatures, as the stems and leaves began to degrade, the plant shifted the main metabolic processes to the root system. It can be seen that the amount of HMW carbohydrates increased threefold compared to the end of summer, but the amount of LMW carbohydrates increased more than eight times during the same period. The distribution of the two carbohydrates relative to each other - the amount of LMW carbohydrates being more than 4.5 times that of HMW carbohydrates - shows that root metabolism became very active as winter approached. These data are consistent with the results of Van den Ende and coworkers (1996). According to their measurements, the levels of free fructose and sucrose peaked around October-November, while that of glucose decreased. This latter event was probably due to the fact that the plant incorporated glucose into fructans. We couldn't sample during the winter period because of the weather conditions, and therefore we do not have data for this season. In the spring, the amount of TSS decreased to less than half of the level measured only half a year earlier. By April, the plant was already in a period of growth, developing the above-ground organs. Thus, following the likely winter peak, the plant mainly mobilized the fructose and sucrose molecules in the stems and leaves. The proportion of high: low molecular weight carbohydrates was 36: 64\%, so the proportion of HMW increased compared to the autumn value, but this was only because most of the oligosaccharides were removed from the root system. 


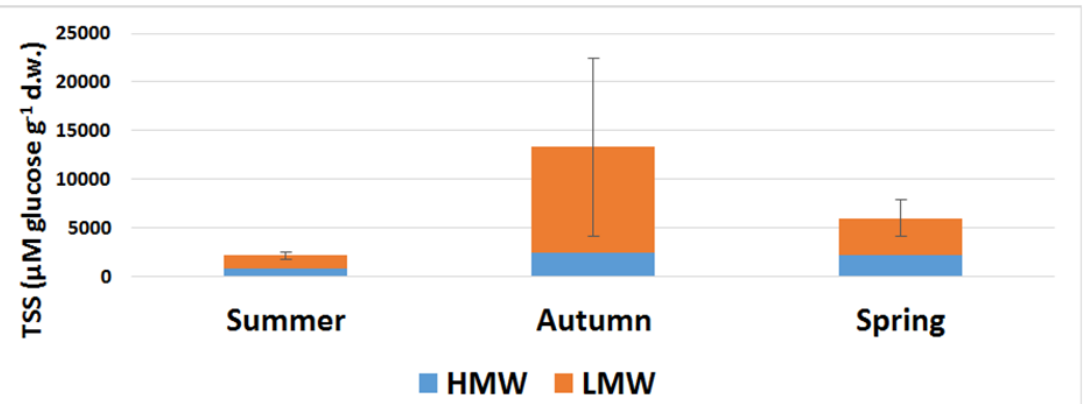

Figure 4. Total soluble sugar content ( $\mu \mathrm{M}$ glucose $\mathrm{g}^{-1} \mathrm{~d}$.w.) of Cichorium intybus root depending on seasonality. HMW (blue column): high molecular weight of soluble carbohydrates; LMW (orange column): low molecular weight of soluble carbohydrates; Error bars are STDs, which concern the sum of HMW + LMW fructans (total fructan), where $n=5$.

The summer fructan content of the chicory root, as in papers of Ernst and coworkers (1996) and Van den Ende and coworkers (1996), was very low (76 $\mu \mathrm{M} \mathrm{g-1}$ d.w.) (Figure 5). This piece of data also demonstrates that below-ground plant parts play an important role during this period, not in storage but in mobilizing the components involved in energy metabolism. In the autumn, the amount of fructan in the root system increased to $409 \mu \mathrm{M} \mathrm{g}^{-1} \mathrm{~d}$.w., more than five times higher than the value at the end of summer. As is the case with other species in the Asteraceae family, with the persistence of low temperatures and the degradation of the aboveground organs, the plant began to accumulate fructan reserves in the roots. This is also evidenced by the high molecular weight fructans polymerization, the HMW: LMW distribution was 56: 44\%. This is also supported by the fact that the proportion of HMW fructans in the proportion of HMW soluble carbohydrates increased threefold compared to summer data. By mid-spring, there was a significant change in the amount of total fructan and HMW-LMW fructans also. Total fructan levels increased above $3000 \mu \mathrm{M} \mathrm{g}^{-1}$ d.w., more than seven times the value five months earlier. However, the most important change occurred in the relative amounts of HMW-LMW fructans, their proportion in April being 3: $97 \%$. As the temperature increased with the onset of spring, degradation of the high molecular weight fructans occured, which resulted in the reintroduction of the stored fructose and glucose molecules into metabolic processes. The following numbers 
show this well: HMW fructans decreased by almost a third, while LMW fructans increased from 180 to $2980 \mu \mathrm{M} \mathrm{g}$ - $^{-1}$ d.w., in just 5 months, an increase of $1600 \%$. There is a striking difference between total summer and spring fructan content. Due to the development of new vegetative and reproductive shoots (stem, leaves, flowers), the plant uses up all the storage carbohydrates. Thus, during the warmer months, it almost completely empties the fructan reserves of the roots. We found that the fraction of fructan molecules: TSS was very low, barely 4\%, approaching the end of the growth phase (Figure 4, 5). During this period, other soluble carbohydrates (mainly sucrose) were accumulated in the roots. This ratio decreased further in the autumn, despite the fact that the plant had begun active fructan synthesis. This decrease is well explained by the results of Van den Ende and coworkers (1996). In spring, with the onset of the growth phase, more than half of the soluble carbohydrates in the roots were present in fructans. HMW fructans accounted for only $4 \%$ of the total soluble HMW carbohydrates, while nearly $78 \%$ of the soluble LMW carbohydrates were fructans (Figure 5). This proves that during the colder months, the plant stored large amounts of fructose and glucose molecules in its roots in polysaccharides, which were degraded to oligosaccharides at the start of the developmental phase (Figure 6), and started an intensive photosynthetic carbon gain by for example the rosette leaves at the beginning of the vegetative period.

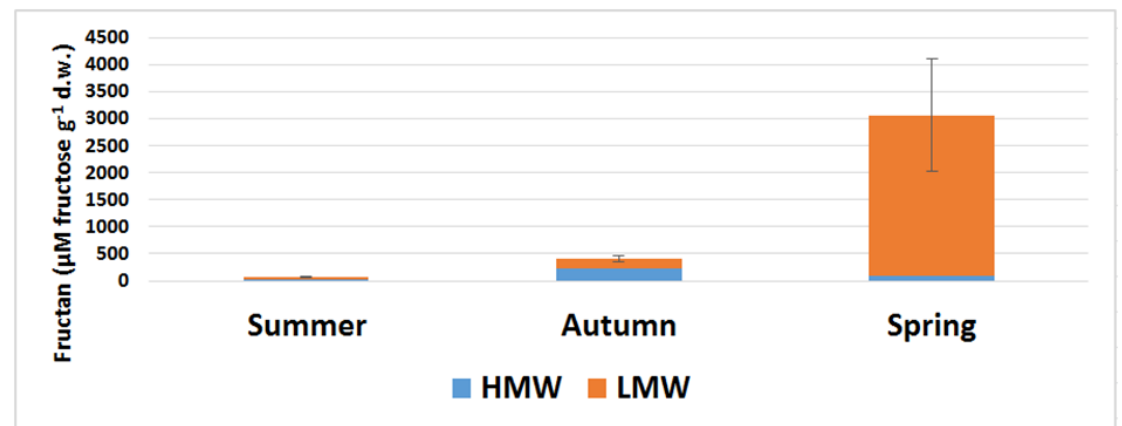

Figure 5. Fructan content $\left(\mu \mathrm{M}\right.$ fructose $\mathrm{g}^{-1}$ d.w.) of Cichorium intybus root depending on seasonality. HMW (blue column): high molecular weight of fructans; LMW (orange column): low molecular weight of fructans; Error bars are STDs, which concern the sum of HMW + LMW fructans (total fructan), where $\mathrm{n}=5$. 

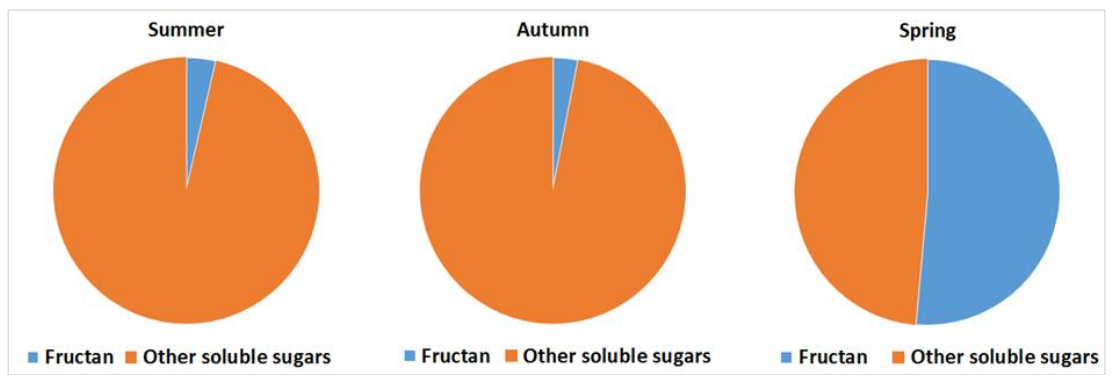

Figure 6. The ratio of fructan (blue) to other soluble carbohydrates (orange) in Cichorium intybus root depending on seasonality. The plant had total soluble carbohydrate reserves of about $2114 \mu \mathrm{M} \mathrm{g}^{-1}$ d.w. in summer, $13273 \mu \mathrm{M} \mathrm{g}^{-1} \mathrm{~d}$.w. in autumn and $5957 \mu \mathrm{M} \mathrm{g}^{-1}$ d.w. in spring.

The total soluble carbohydrate content of the stem of Dactylis glomerata was lower at the end of summer $\left(870 \mu \mathrm{M} \mathrm{g}^{-1}\right.$ d.w. $)$ than in spring (Figure 7). By this time of the year, the plant had already used up most of its sugar reserves. This result is consistent with the results of Belesky and coworkers (2006). They conducted investigations with Dactylis in the northeastern United States during the same periods, under conditions similar to those prevailing in our country. The amount of HMW carbohydrates measured in August was more than $560 \mu \mathrm{M} \mathrm{g}^{-1} \mathrm{~d} . w$. ., which is almost $65 \%$ of the total amount. By this time, the metabolic activity of the plant was not as high as in the previous period. In the spring of the following year, there was a significant change in TSS values. The spring value was 4.5 times the summer value (Figure 7). This change in the total soluble sugar content is also characteristic of forage plants and the Poales. By the end of April, the main task for the plant was to produce new leaves and flowers. The HMW: LMW carbohydrate ratio also changed, with LMW carbohydrates accounting for $64 \%$ of the total. HMW carbohydrate increased to 2.5 times the value of the previous summer. Due to more intensive metabolic processes, the plant was able to accumulate more reserves in its stem. This is the plant's strategy for surviving the summer drought. 


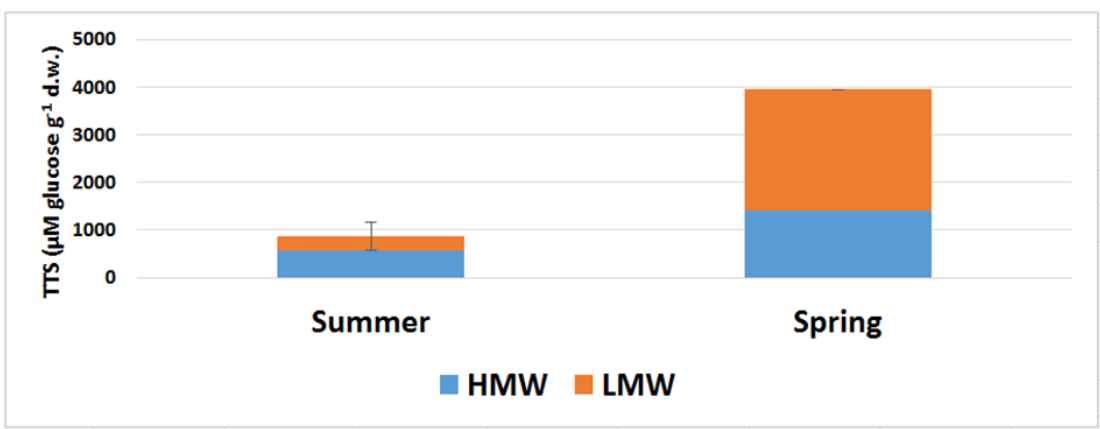

Figure 7. Total soluble sugar content ( $\mu \mathrm{M}$ glucose $\mathrm{g}^{-1}$ d.w.) of Dactylis glomerata stem depending on seasonality. HMW (blue column): high molecular weight of soluble carbohydrates; LMW (orange column): low molecular weight of soluble carbohydrates; Error bars are STDs, which concern the sum of HMW + LMW fructans (total fructan), where $n=5$.

By the end of summer, as in some other species belonging to Poaceae, a large amount of fructan had accumulated in the stem (Figure 9). This result is consistent with the measurements of Sanada and coworkers (2007), who measured an autumn peak. The HMW: LMW ratios were 64: $36 \%$ by the end of summer. This means that most of the fructan molecules were present in the highly polymerized state, and with this reserve the plant prepared for the fall/winter period. By mid-spring, there was a significant decrease in both total fructan and HMW-LMW fructans. The amount of TSS fell to almost a seventh. In the growth period the plant virtually completely depleted its fructan polymer reserve. In this season the HMW fructans were only $6 \%$ of the value of HMW fructans at the end of the summer. The change in LMW fructans was not so drastic, falling to $30 \%$ in comparison with the August value. HMW: LMW fructan contents relative to each other showed a distribution of 29: $71 \%$. The few fructan molecules that were present in the stem were largely in oligosaccharides. 


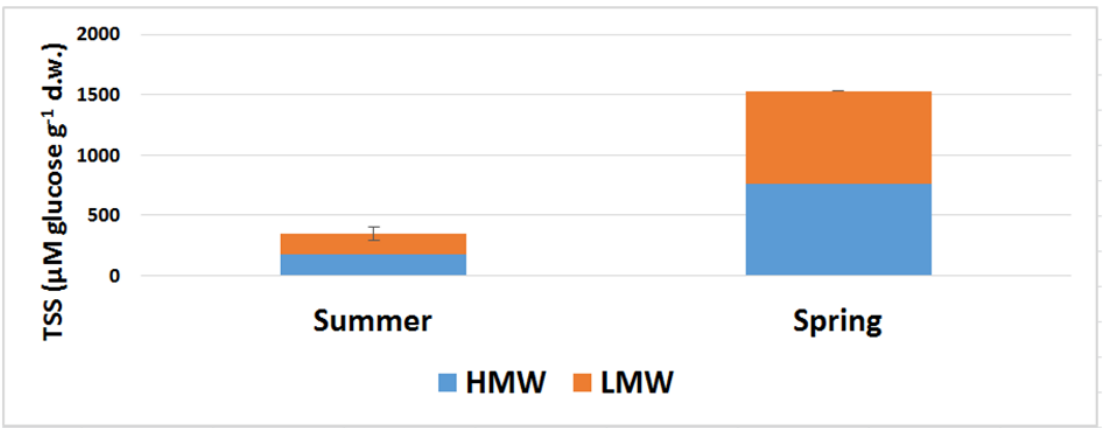

Figure 8. Total soluble sugar content ( $\mu \mathrm{M}$ glucose $\mathrm{g}^{-1} \mathrm{~d}$.w.) of Dactylis glomerata leaf depending on seasonality. HMW (blue column): high molecular weight of soluble carbohydrates; LMW (orange column): low molecular weight of soluble carbohydrates; Error bars are STDs, which concern the sum of HMW + LMW fructans (total fructan), where $n=5$.

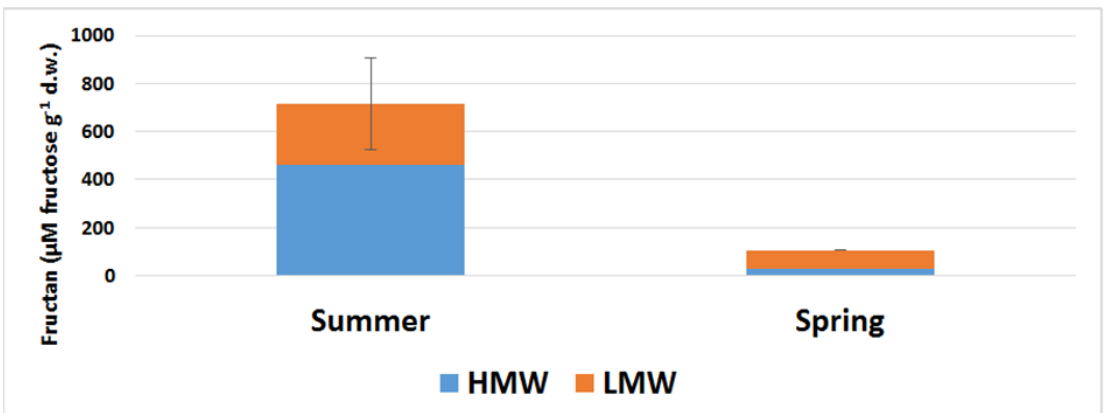

Figure 9. Fructan content ( $\mu \mathrm{M}$ fructose $\mathrm{g}^{-1}$ d.w.) of Dactylis glomerata stem depending on seasonality. HMW (blue column): high molecular weight of fructans; LMW (orange column): low molecular weight of fructans; Error bars are STDs, which concern the sum of HMW + LMW fructans (total fructan), where $n=5$.

Fructans were present in an astounding proportion of the total soluble sugars at the end of the summer, more than $82 \%$ of the TSS (Figure 11). This is one of the reasons why the forage crops are harvested in the summer, as fructans improve their quality. In the spring, the opposite was true. Fructans accounted for less than 3\% of the total soluble carbohydrates. This piece of data also proves that the plant needed the monosaccharides stored in the fructans and released them (Figure 9). The soluble carbohydrate content measured in the leaf of D. glomerata, as in the case of the stem, was generally lower at the end of summer than in spring, less than 350 $\mu \mathrm{M} \mathrm{g}^{-1}$ d.w. (Figure 8). At this time of the year, the degradation in 
the above-ground parts of the plant had already begun, mainly in the leaves. This result is in line with the findings of Belesky and coworkers (2006). The amounts of the high and the low molecular weight carbohydrates measured in August were the same (Figure 8). This means that the leaves had a well-balanced storage and active use of soluble sugars. By the end of April, there was a significant change in TSS content. It increased more than fourfold compared to the summer value, which is also consistent with the results of Belesky and coworkers (2006). In spring time intensive photosynthesis resulted in high carbohydrate production in the renewed leaves. It is interesting, however, that the HMW: LMW ratio was 50: $50 \%$, as in the summer. It is likely that the distribution of soluble poly-, oligo- and monosaccharides in the leaves is constantly balanced.

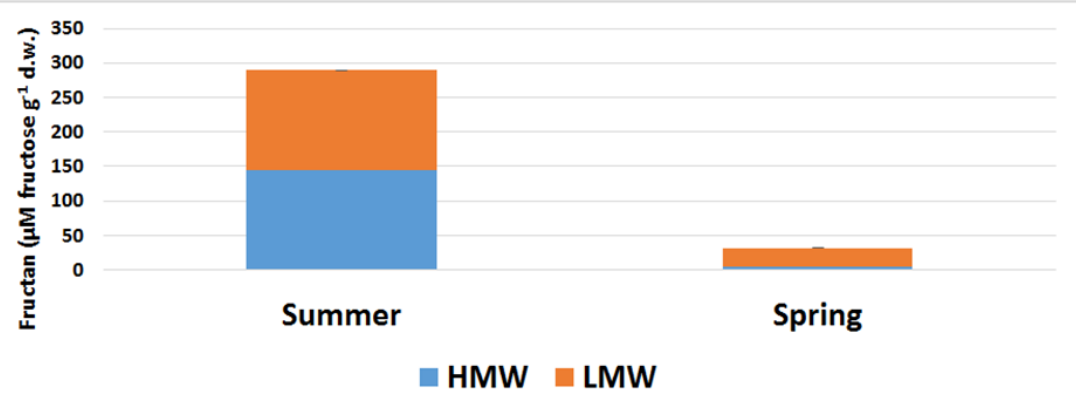

Figure 10. Fructan content $\left(\mu \mathrm{M}\right.$ fructose $\mathrm{g}^{-1}$ d.w.) of Dactylis glomerata leaf depending on seasonality. HMW (blue column): high molecular weight of fructans; LMW (orange column): low molecular weight of fructans; Error bars are STDs, which concern the sum of HMW + LMW fructans (total fructan), where $n=5$.

The fructan content of the leaf of D. glomerata in August, as in the case of the stem, was higher than in spring, and was $\sim 290 \mu \mathrm{M}$ $\mathrm{g}^{-1}$ d.w. (Figure 10). By the end of the growing season, the plant leaf had accumulated relatively high levels of fructans as in forage crops. Interestingly, the distribution of HMW: LMW was 50-50\%. It is likely that in the following months, the plant began to gradually utilize the energy stored in fructans, which primarily meant the depolymerization of high molecular weight fructans, which would explain the change in the spring. In April, fructan content was only $33 \mu \mathrm{M} \mathrm{g}^{-1} \mathrm{~d}$.w.. This represents a reduction of nearly $90 \%$ over the last 7 months (Figure 10). The proportion of HMW: LMW also 
changed, their proportion being 16: 84\%. The fructan polymers were practically completely degraded, although not much of the smaller molecules remained in the leaves. The number of shortchain fructans in the leaf decreased to nearly one-fifth, while only $3 \%$ of the summer amount remained in HMW sugars. Results show (Figure 11) that at the end of summer, as in the stem, fructans accounted for the majority of soluble carbohydrates in the leaf, representing $83 \%$. In spring, this ratio was reversed, with only $2 \%$ of the total soluble carbohydrate content being fructan molecules. The fresh shoots mobilized the monosaccharides from the fructan reserve. Comparing the stem and leaf values, TSS in the stem was 2.5-fold higher in the summer and 2.6-fold higher in the spring. Total fructan content was 2.5-fold higher in the summer and 3.3fold higher in the stem than in the leaves. As Waite and Boyd (1953) and Belesky and coworkers (2006) described, regardless of the season, soluble sugars, including fructans, are much more present in the above-ground parts of the shoot, especially in the stem. This feature is also typical of the Poales order. Therefore, for feeding purposes the stem is considered to be more valuable than the leaf parts. However, we found great similarities in the change of the amount of soluble carbohydrate and fructan, and thus in their relative distribution, between the two seasons. The amount of TSS decreased in the same proportion as the fructan did between the two sampling periods. Although less efficient in the autumn and winter period, photosynthesis occurred, but the plant consumed most of its energy reserves, so storage sugars were only present in small amounts in the spring. The ability of fructan accumulation in this plant has developed not only to withstand frost but also to survive the summer heat and drought, so it is important for the plant to synthesize it in all parts and to increase its amount until warmer temperatures arrive. 


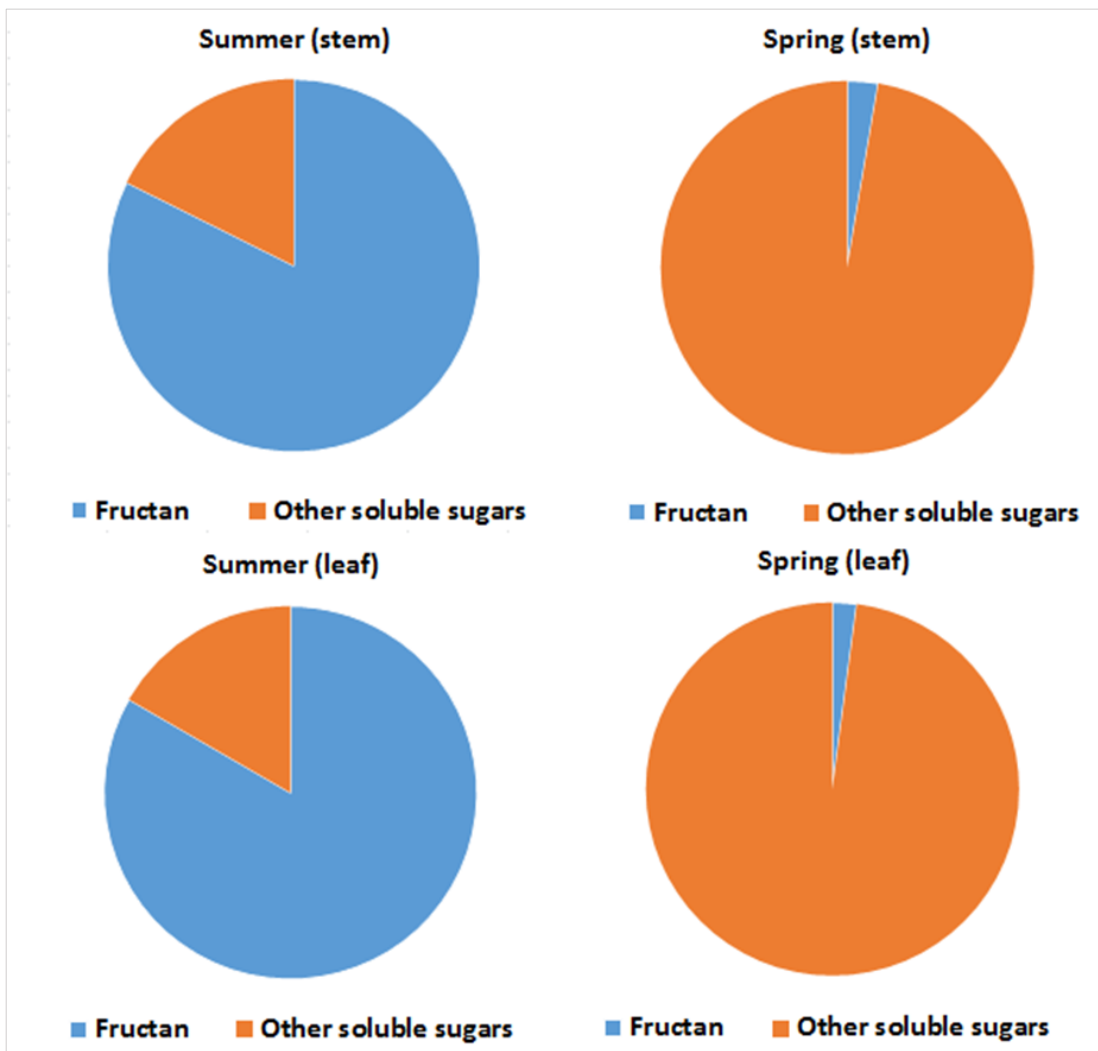

Figure 11. The ratio of fructan (blue) to other soluble carbohydrates (orange) in Dactylis glomerata stem and leaf depending on seasonality. The plant had total soluble carbohydrate reserves of about $870 \mu \mathrm{M} \mathrm{g}^{-1} \mathrm{~d}$.w. in the stem and $347 \mu \mathrm{M} \mathrm{g}^{-1}$ d.w. in the leaf in summer, $3944 \mu \mathrm{M} \mathrm{g}^{-1} \mathrm{~d}$.w. in the stem and $1527 \mu \mathrm{M} \mathrm{g}^{-1} \mathrm{~d}$.w. in the leaf in spring.

Comparison of the TSS content of the two plants shows $H$. tuberosus peaks in summer and $C$. intybus in autumn. This is because the former blooms from late summer to late autumn, the latter from June to November. As a result, the Jerusalem artichoke needs to use less storage carbohydrate to develop inflorescence and thus it can accumulate. Another influencing factor is that due to the Hungarian macroclimatic conditions, it does not produce any fruit, while the $C$. intybus does. This is also a carbohydrate consuming process. D. glomerata shows the species- and orderspecific differences to the other two plants. The low summer TSS content suggests that most of it is incorporated into structural 
components and used up for growth. It is important to note that while in the case of $H$. tuberosus and $C$. intybus below-ground storage organs were examined, in D. glomerata we examined above-ground organs. We also found a large difference in fructan content between the plants of the two orders. In the below-ground organs (tuber, root) of the Asteraceae species following the lowactivity summer/autumn synthesis, the amount of fructan oligosaccharides, mainly LMW, is likely to have increased dramatically in winter in the case of the Jerusalem artichoke, and also in chicory (based on spring data only). In the case of $D$. glomerata, based on only the analysis of the the above-ground organs (stem end leaves), the amount of fructans peaked in the fall in order for the plant to survive winter frosts. We could draw the same conclusions as Yoshida and Tamura (2011). During the physiological process that is called 'hardening', carbohydrates are accumulated in their tissues, therefore plants can acclimate to cold months by increasing their tolerance to freezing.
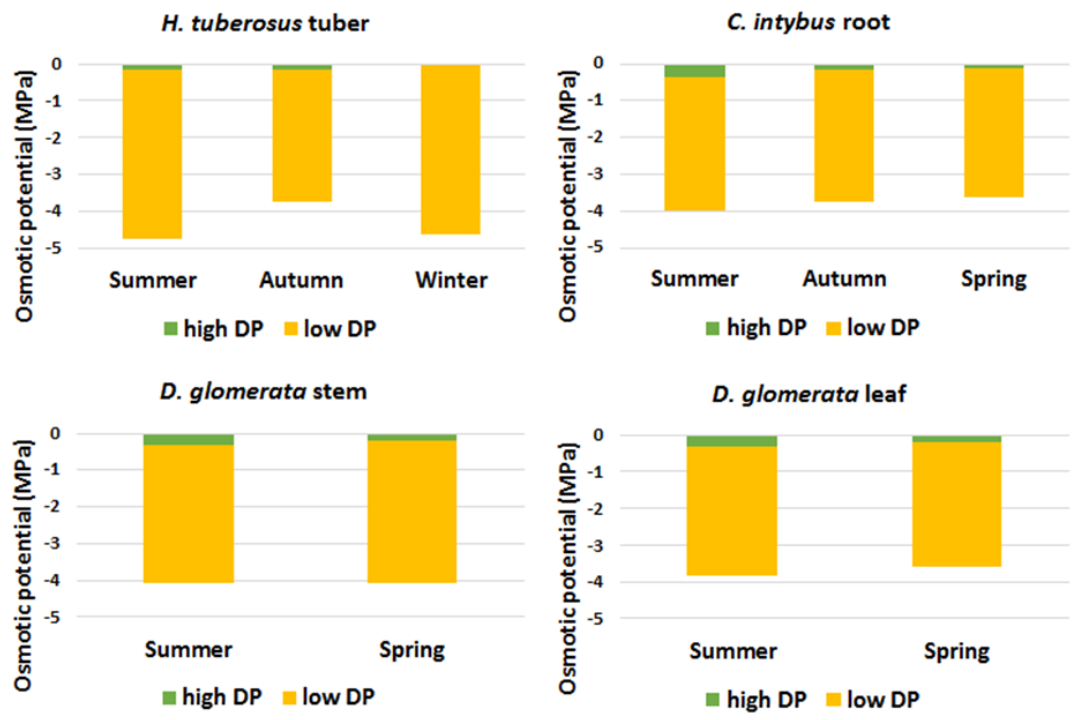

Figure 12. Osmotic potential (MPa) of $H$. tuberosus tuber, $C$. intybus root and Dactylis glomerata stem and leaf depending on seasonality. Osmotic potential values of the plant extract containing soluble carbohydrates with a high degree of polimerization (DP) (green), and a low degree of polimerization (DP) (yellow). 
Osmotic potential, as a component of water potential, results from inorganic and organic molecules within plant extracts. As the concentration of molecules increases, the osmotic potential of the tissue is reduced. The more molecules present, the more negative the osmotic, or solute, potential is. Our hypothesis was that the supernatant of the fructan-accumulating plant extract contained more fructan molecules with a low degree of polymerization, and the sediment less molecules but with a high degree of polymerization. The soluble carbohydrates are an important but not exclusive component of the osmotic (solute) potential. HMW fructans and other carbohydrates in the sediment contribute little to the osmotic potential. LMW fructans and other carbohydrates in the supernatant accounted for a significant proportion of the osmotic potential.The values of osmotic potentials (Figure 13) prove that the amount of soluble carbohydrates correlates with them. As the amount of enzymes, other proteins, amino acids, polyols, quaternary ammonium derivatives and dissolved minerals - as other possible osmoregulators - were not measured, their influence levels could not be determined. The tuber of the Jerusalem artichoke had the highest osmotic potential, partly because it had the largest amounts of TSS and, on the other hand, the function of the tuber was different from other organs and other physiological processes were involved, mainly water and nutrient storage. Although the values of the $C$. intybus were lower, they did not correlate so well with the given TSS contents. The physiological processes of the root are also different: uptake of water and minerals, lateral root formation, and hormone synthesis, which all have a significant effect on the osmotic potential. We measured higher values for the D. glomerata stem than for the $C$. intybus, regardless of the difference in TSS content. In addition to transporting many substances in the stem - nutrients, hormones, water, ions - photosynthesis, the components used and produced by have a significant effect on the osmotic potential. Although the leaf is the main organ of photosynthesis, the production and use of nutrients is more balanced than that in the stem, so the osmotic potential values of the leaf are slightly more positive. In the case of the Jerusalem artichoke tuber, the actual amount of TSS, since it is not a photosynthetic organ, was more closely related to the change in osmotic potential than in the other two plants. This relationship may have been due to the circumstance described above for the 
Jerusalem artichoke, namely that it blooms relatively shortly and yields no fruit, unlike C. intybus and D. glomerata (Figure 13). Due to the biological processes required for these, significant protein, carbohydrate and ion metabolism occurs in the plant, so these factors are thought to 'have distorted' or modified the degree of relationship between the two values (change in TSS amount vs osmotic potential). As also contributed to this the fact that in the case of $D$. glomerata an above-ground organ was investigated, which was also influenced the values of osmotic potentials.

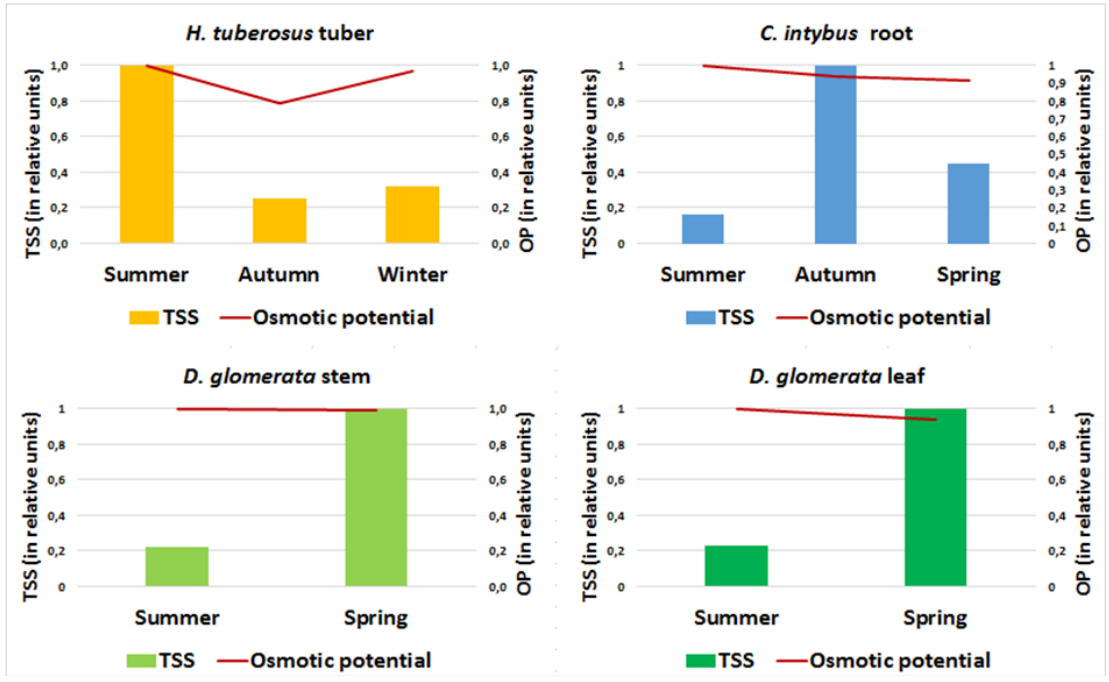

Figure 13. Relationship between total soluble carbohydrate content (TSS) and osmotic potential (OP) (both in relative units) of $H$. tuberosus tuber, $C$. intybus root and Dactylis glomerata stem and leaf depending on seasonality. 


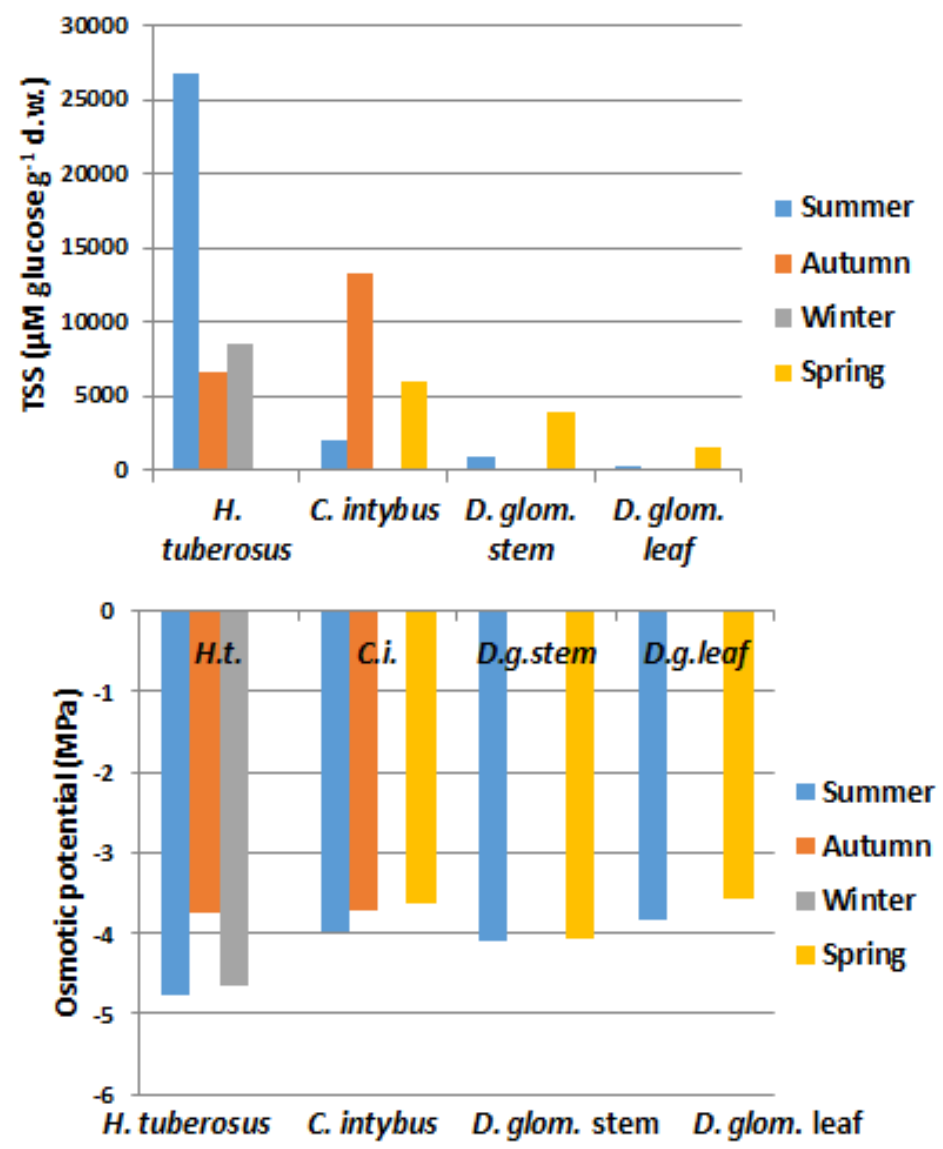

Figure 14. The average values of total soluble carbohydrate content (TSS) (above graph) and osmotic potential (OP) (below graph) (both in absolute values) of $H$. tuberosus tuber, $C$. intybus root and Dactylis glomerata stem and leaf depending on seasonality.

Thin layer chromatography (TLC) was used to determine the quality of the soluble carbohydrates and to measure their degree of polymerization. We found differences between the TSS of the three plants and between the supernatant and sediment extracts from that time of the year. There is a clear difference between the chromatograms of the supernatant and the sediment samples, since the former contains the oligosaccharides with lower DP, which can be separated by this technique, and the latter the high molecular weight ones. The aforementioned difference was most evident in 
the Asteraceae, since higher amounts of fructans were present in their supernatants (with lower DP), whereas running D. glomerata samples confirmed the earlier finding that their fructans are mainly stored with higher DP. The DP of fructans in D. glomerata's supernatants is also different from that in the studied Asteraceae plants. Molecules with a higher degree of polymerization are 'stuck' near the starting point of the TLC. In the case of the Jerusalem artichoke (Figure 15), the chromatogram of the summer supernatant sample is the palest compared to its autumn and winter samples. This confirms the values obtained when quantifying the fructan content, namely that fructans were present in the summer supernatant in the smallest amounts (Figure 5). The differences in sediment chromatograms may be due to the fact that the fructans continued to undergo the most intensive polymerisation in the autumn, so that the oligosaccharides were detectable even from the sediment at that time, whereas it appears that the sediment was practically emptied of fructans in winter. Interestingly, although much higher amounts of fructans were present in winter, the chromatogram of the autumn supernatant sample appears to be more contrasted. The difference between the data of the two seasons was that while in the autumn enzymatic processes for accumulation or storage were in progress, by the end of winter they were already oriented towards usage. In terms of degree of polymerization, the presence of DP 3-12 fructans was well detectable in all seasons. The major soluble carbohydrates in $H$. tuberosus are sucrose and a homologous series of fructans including the trisaccharide 1- kestose, which is characteristic of inulin-type fructans (Marschall et al. 1998). Glucose and fructose were present at considerably lower concentration. We used sucrose (DP $=2$ ) and the extract $H$. tuberosus tuber (DP = 3-12) as standards, no trisaccharides (neokestose, isokestose, cestose; DP = 3). For inulin reference the well-known chromatographic data of $H$. tuberosus tuber extract were used (Cairns and Pollock 1988, Smouter and Simpson 1991). 


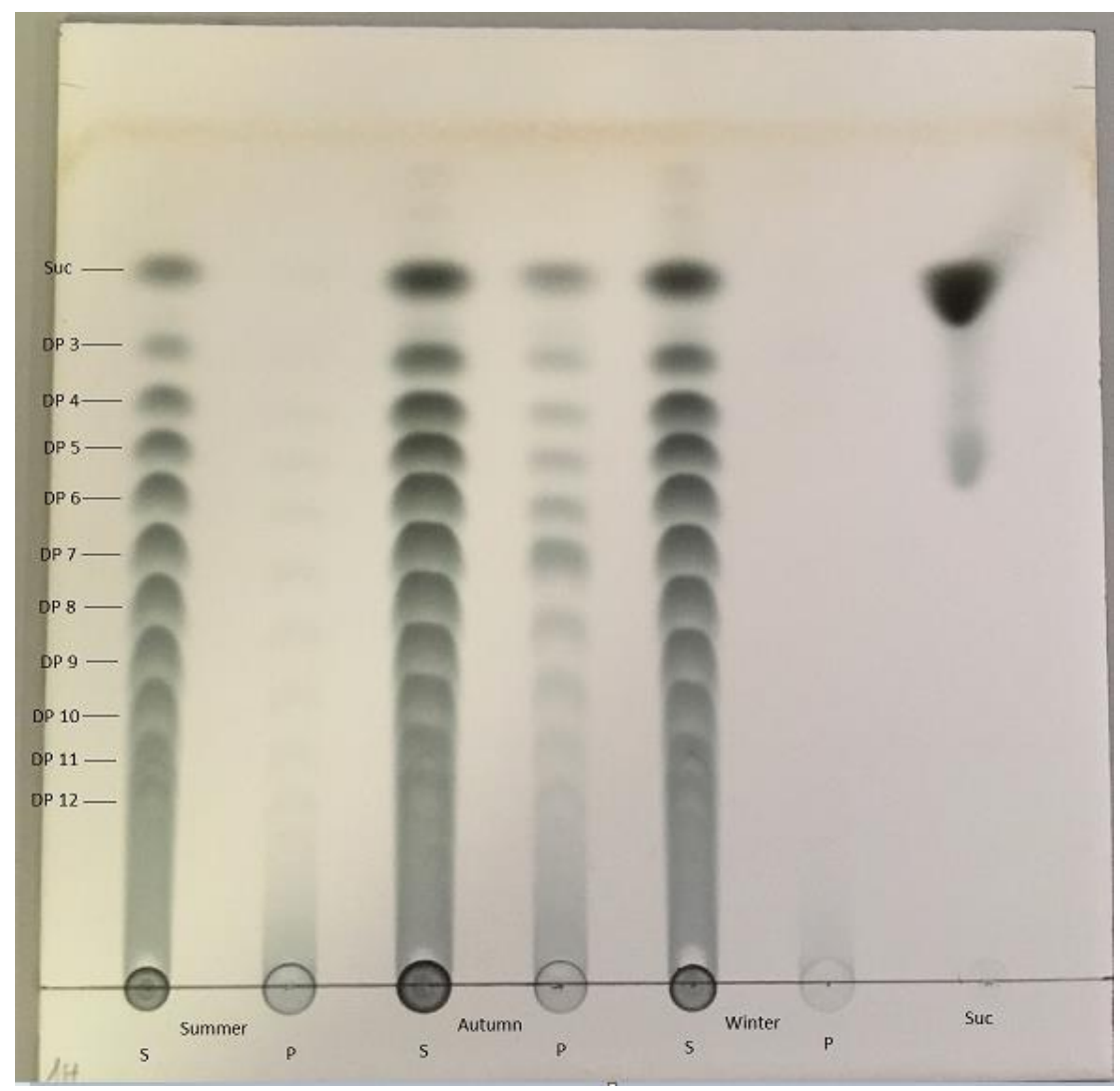

Figure 15. Thin layer chromatography of fructans from H. tuberosus tuber depending on seasonality (summer, autumn, winter). Plant tissue was extracted with $80 \%$ ethanol followed by hot water (Marschall et al. 1998). $25 \mu \mathrm{l}$ of supernatant (S) and also pellet (P) extracts were used for TLC. SUC, $10 \mu \mathrm{l}$ of $10 \mathrm{mM}$ sucrose; DP 3-DP 12, fructans of degree of polymerization 3-12.

The appearance of the TL chromatograms in the case of chicory (Figure 16) is not as marked as in the case of the Jerusalem artichoke. The quantitative determination revealed that smaller fructan amounts were measured in this species. There is a large difference between the chromatograms of the autumn and spring supernatants. This can be explained by the fact that, as in the case of the Jerusalem artichoke, the fructans are polymerized in the fall and stored until mid-spring. Both summer and autumn samples showed the presence of DP 3-12 fructans. TLC showed that fructans form a homologous series of increasing DP in a similar manner to 
fructans in $H$. tuberosus and contain the isokestose-type trisaccharide.

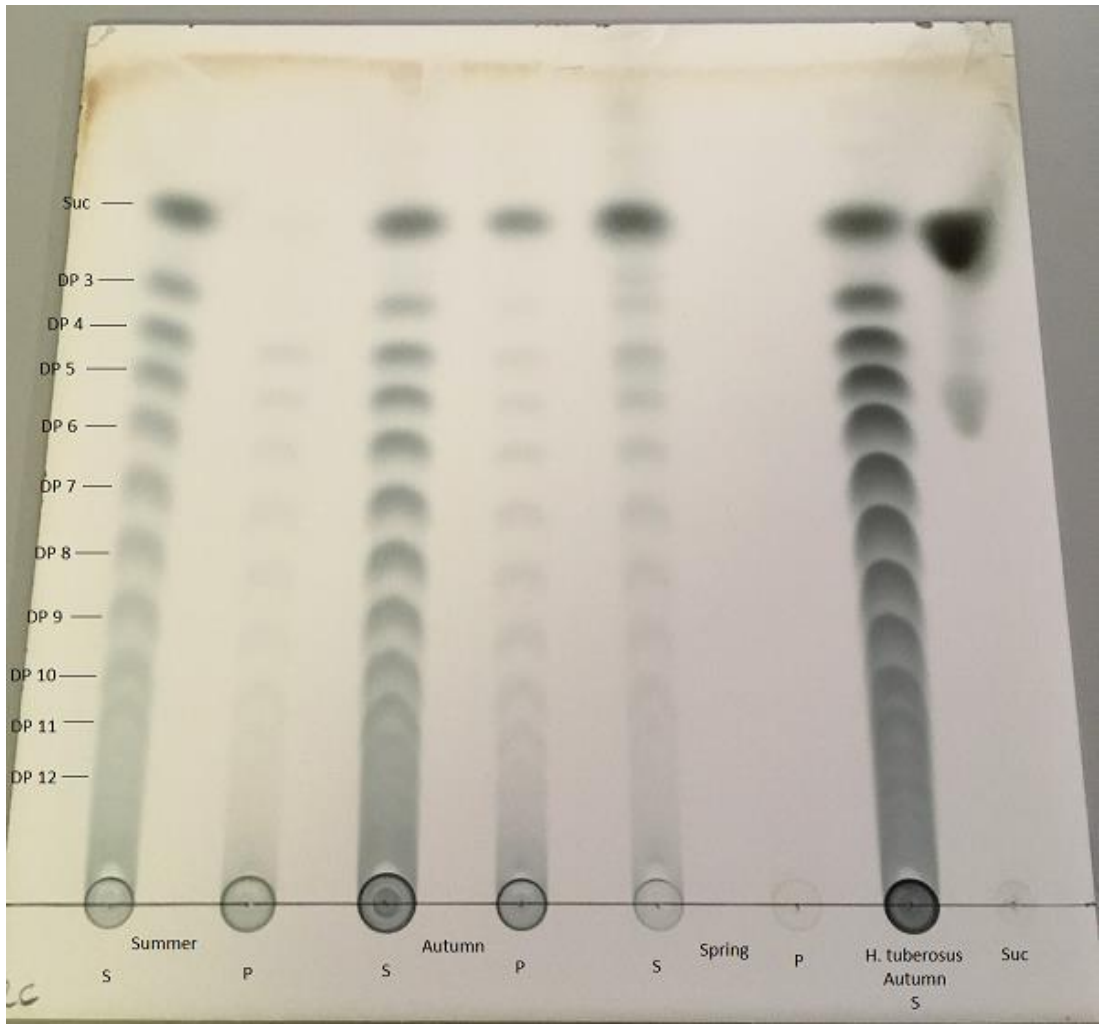

Figure 16. Thin layer chromatography of fructans from $C$. intybus root depending on seasonality (summer, autumn, spring). Plant tissue was extracted with $80 \%$ ethanol followed by hot water (Marschall et al. 1998). $25 \mu \mathrm{l}$ of supernatant (S) and also pellet (P) extracts were used for TLC. SUC, $10 \mu \mathrm{l}$ of $10 \mathrm{mM}$ sucrose; DP 3-DP 12 , fructans of degree of polymerization $3-12$. We used sucrose (DP $=2$ ) and the extract $H$. tuberosus tuber (DP $=3-20$ ) as standards, no trisaccharides (neokestose, isokestose, cestose; $\mathrm{DP}=3$ ). 


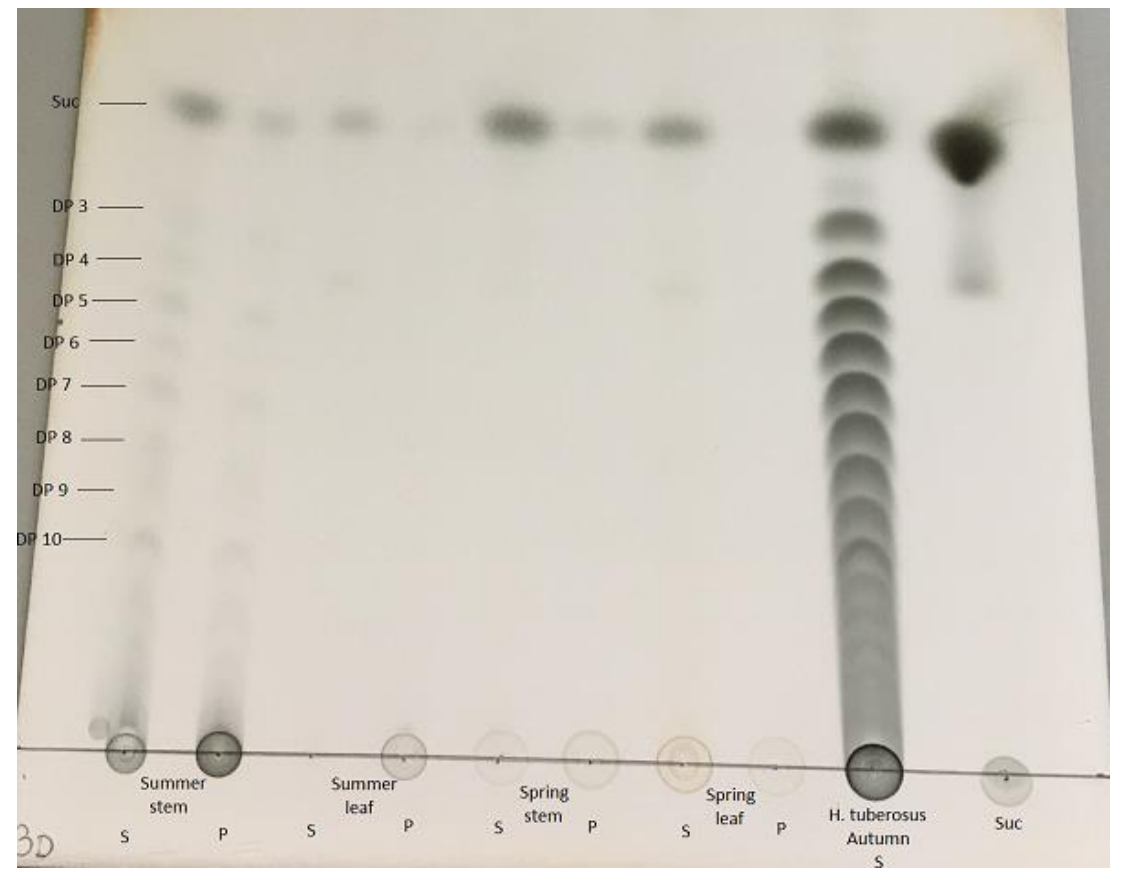

Figure 17. Thin layer chromatography of fructans from D. glomerata stem and leaf depending on seasonality (summer, spring). Plant tissue was extracted with $80 \%$ ethanol followed by hot water (Marschall et al. 1998). $25 \mu \mathrm{l}$ of supernatant (S) and also pellet (P) extracts were used for TLC. SUC, $10 \mu \mathrm{l}$ of $10 \mathrm{mM}$ sucrose; DP 3-DP 10 , fructans of degree of polymerization $3-10$. We used sucrose (DP = 2) and the extract $H$. tuberosus tuber (DP $=3-20$ ) as standards, no trisaccharides (neokestose, isokestose, cestose; $\mathrm{DP}=3$ ).

The separation of the fructans of $D$. glomerata by TLC (Figure 17) gave a completely different result, and its chromatograms were faint. We could detect a homolog series of fructan oligosaccharides with DP 3-10 only from the supernatant of the summer stem sample, but this is negligible compared to the Jerusalem artichoke's autumn supernatant. In the spring samples, the homologous series of fructans between DP 3 and 10 was not visible with the consistently applied loading sample amount. Interestingly, the presence of sucrose was most detectable in the case of both stems and leaves in spring, which could mean more intensive depolymerization processes. Since fructan levels in the summer supernatant samples were measured at a few hundred $\mu \mathrm{M} \mathrm{g}^{-1} \mathrm{~d}$.w., it is likely that their degree of polymerization is greater than ten. By this method, carbohydrates with DP $>10$ are difficult to detect. The 
trisacharide kestose mobility was different from the chicory inulintype isokestose, which would prove that the D. glomerata contains other types of fructans. It contains levan-type fructans (Suzuki 1989, Bonnet et al. 1997).

\section{CONCLUSION}

Our experimental results show that fructans play a major role in the physiological processes of the three species. The two species belonging to the Asteraceae tend to accumulate low molecular weight oligosaccharides and the species belonging to the Poaceae accumulates medium and high molecular weight oligo- and polysaccharides to increase physiological performance, stress tolerance. Taking into account the climatic and weather conditions, we concluded that the fructan production of the plants belonging to the Asteraceae investigated in North Hungary is mainly influenced by the cold, while the species belonging to the Poaceae is influenced by the temperature factors and also by the amount of precipitation. The tuber of $H$. tuberosus is the main storage organ for protection against stress caused by low temperature. Our results confirm that this species developed its fructan synthesis ability largely through defense. The molecules of free glucose, fructose and sucrose in the soluble carbohydrate pool gradually used to synthesize fructans. The species increased the synthesis of fructans as the temperature decreased. While only a little amount of inulin-type fructans was stored in the tubers during the summer, the plant began to intensify their synthesis and polymerization of fructan chains in the autumn. In winter, when average daily temperatures were at their lowest, the Jerusalem artichoke met the conditions for survival by depolymerization of fructan molecules and by maintaining its oligosaccharides in extensive metabolic processes. A related Asteraceae species, $C$. intybus, showed similar characteristics in its root, but there were also differences. These arose because this species blooms longer than the Jerusalem artichoke and usually yields fruit as well. Therefore the time available for fructan accumulation is shorter and starts later when the temperature is already lower. But like H. tuberosus, this plant also produced monoand disaccharides from WSC and used it for their synthesis. In the summer, fructans were only minimally detected in the samples, but by the end of the autumn, significant fructan synthesis had taken 
place. Data from mid-spring showed that fructan molecules were still present in large amounts in the root, and the energy and carbon stored in them could be used for growing new shoots, leaves and flowers. This assumption is confirmed by the large decrease in fructan content of the root measured at the end of summer.

The carbohydrate and, mostly, the fructan metabolism of $D$. glomerata differs from that of the previous two plants. This species produces levan-type fructans not only against cold stress but also against summer drought. Examining its stem and leaf, we found great similarity in the dynamics of fructan amount alteration. However, by the end of the summer, the amount of fructans in the stem was twice as high as in the leaf. The reason for this is that the stem acts as a central distribution channel and as a partly winterresistant storage organ, so this ratio is similar at any time of the year. With the passing of winter and the coming of the growing season, D. glomerata released the glucose and fructose stored in the fructans to produce new shoots and leaves, and then flowers and seeds.

It is important to know that the amount of non-structural carbohydrates, i.e. fructans, decreases with increasing precipitation. Fodder plant producers and pet nutritionists can draw important conclusions from the results of these studies, given the importance of the amount of carbohydrate a pet consumes in a day.

Two other areas, the food and pharmaceutical industries, can also benefit from the research results. Inulin-type fructans are a popular dietary supplement, but can be a good substitute for beet sugar and other sweeteners. Because the human body does not produce the enzyme needed to break it down, it cannot be absorbed. This fact is very useful in diabetics because, although sweet, it does not raise blood sugar levels. This allows diabetics to consume tubers (e.g. the Jerusalem artichoke) or onions containing inulin.

The three fructan-accumulating species we examined are wellestablished model plants in this research area. To the best of our knowledge, no studies have been conducted to date on how the total soluble carbohydrate (TSS) content, quantitative and qualitative fructan content and osmotic potential change under the 
same environmental conditions in the 3 plant species, collected at the same time, as a function of seasonality.

Acknowledgement - The first author is grateful to Albert Vermes for reading and correcting the English of the manuscript and also for the financial support of the grant EFOP-3.6.1-16-2016-00001 ("Complex improvement of research capacities and services at Eszterházy Károly University").

\section{REFERENCES}

Abeynayake, S.W., Etzerodt, T.P., JonavičienE K., Byrne, S., Asp,T. \& Boelt, B. (2015). Fructan metabolism and changes in fructan composition during cold acclimation in perennial ryegrass. Frontiers in Plant Science 6: 329. https://doi.org/10.3389/fpls.2015.00329

AvigAD, G. \& DEY, P.M. (1997). 4 - Carbohydrate Metabolism: Storage Carbohydrates. In: Dey, P.M. \& Harborne, J.B. (eds.) Plant Biochemistry. Academic Press, pp. 143-204.

Bach, V., Clausen, M.R. \& Edenblos, M. (2015). Production of Jerusalem artichoke (Helianthus tuberosus L.) and impact on inulin and phenolic compounds. Processing and Impact on Active Components in Food, pp. 97-102. https://doi.org/10.1016/B978-0-12-404699-3.00012-3

BAJJI, M., LUTTS, S. \& KinET, J.M. (2001). Water deficit effects on solute contribution to osmotic adjustment as a function of leaf ageing in three durum wheat (Triticum durum Desf.) cultivars performing differently in arid conditions. Plant Science 160: 669-681. https://doi.org/10.1016/S0168-9452(00)00443-X

BANCAL, P. \& TRIBOI, E. (1993). Temperature effect on fructan oligomer contents and fructan-related enzyme activites in stems of wheat (Triticum aestivum L.) during grain filling. New Phytologist 123: 247-253. https://doi.org/10.1111/j.1469-8137.1993.tb03732.x

Belesky, D., ChatTerton, N.J. \& NeEL, J.P.S. (2006). Dactylis glomerata growing along a light gradient in the central appalachian region of the eastern USA: III. Nonstructural carbohydrates and nutritive value. Agroforestry Systems 67: 5161. https://link.springer.com/article/10.1007/s10457-005-1112-6

BonnetT, G.D., Sims, I.M., John, J.A.S. \& Simpson, R.J. (1994). Purification and characterization of fructans with $\beta$-2,1- and $\beta$-2,6-glycosidic linkages suitable for enzyme studies. New Phytologist 127: 261-269. https://doi.org/10.1111/j.1469-8137.1994.tb04277.x

BonnetT, G.D., Sims, I.M., Simpson, R.J. \& CAiRnS, A. J. (1997). Structural diversity of fructan in relation to the taxonomy of Poaceae. The New Phytologist 136(1): 11-17. https://doi.org/10.1111/j.1469-8137.1997.tb04726.x

CAIRns, A.I. \& AshTon, J.E. (1993). Species-dependent patterns of fructan synthesis by enzymes from excised leaves of oat, wheat, barley and timothy. New Phytologist 124: 381-388.

https://doi.org/10.1111/j.1469-8137.1993.tb03828.x

CAirns, A.J. \& Pollock, C.J. (1988). Fructan biosynthesis in excised leaves of Lolium temulentum L. I. Chromatographic characterisation of oligofructans and their labelling patterns following ${ }^{14} \mathrm{CO}_{2}$ feeding. New Phytologist 109: 399-405. 
https://doi.org/10.1111/j.1469-8137.1988.tb03715.x

Chatterton, N.J., Harrison, P.A., BennetT, J.H. \& Asay, K.H. (1989). Carbohydrate partitioning in 185 accessions of Gramineae grown under warm and cool temperatures. Journal of Plant physiology 134(2): 169-179.

https://doi.org/10.1016/S0176-1617(89)80051-3

Chatterton, N.J., WatTs, K.A., Jensen, K.B., Harrison, P.A. \& Horton, W.H. (2006). Nonstructural carbohydrates in oat forage. Journal of Nutrition 136: 21112113.

De Carvalho, M.A.M., Zaidan, L.B.P. \& Dietrich, S.M.C. (1997). Growth and fructan content of plants of Vernonia herbacea (Asteraceae) regenerated from rhizophores. New Phytologist 136: 153-161.

https://doi.org/10.1046/j.1469-8137.1997.00724.x

De Moraes, M.G., De Carvalho, M.A.M., Franco, A.C., Pollock, C.J. \& De Cássia Leone Figueiredo-Ribeiro, R. (2016). Fire and drought: soluble carbohydrate storage and survival mechanisms in herbaceous plants from the Cerrado. BioScience 66(2): 107-117. https://doi.org/10.1093/biosci/biv178

Dias-Tagliacozzo, G.M., De Cássia, L., Figueiredo-Riberio, R., Carvalho M.A.M. \& DiETRICH, S.M.C. (1999). Fructan variation in the rhizophores of Vernonia herbacea (Vell.) Rusby, as influenced by temperature. Brazilian Journal of Botany 22(2): 267-273.

http://dx.doi.org/10.1590/S0100-84041999000500007

Dubois, M., Gilles, K.A., Hamilton, J.K., Rebers, P.A. \& Smith, F. (1956). Colorimetric method for determination of sugars and related substances. Analytical Chemistry 28: 350-356. https://doi.org/10.1021/ac60111a017

ERnST, M., CHATTERTON, N.J. \& HARRISON, P.A. (1995). Carbohydrate changes in chicory (Cichorium intybus L. var. foliosum) during growth and storage. Scientia Horticulturae 63(3-4): 251-261.

https://doi.org/10.1016/0304-4238(95)00815-B

Ernst, M., Chatterton, N.J. \& Harrison, P.A. (1996). Purification and characterization of a new fructan series from species of Asteraceae. New Phytologist 132(1): 63-66.

https://doi.org/10.1111/j.1469-8137.1996.tb04509.x

FARRAR, J.F. (1993). Carbon partitioning. In: Hall, D.O., SCURlock, J.M.O, BolhaRNordenKampF, H.R., LeEgood, R.C. \& LonG, S.P. (eds.): Photosynthesis and Production in a Changing Environment. A Laboratory Manual. Springer, Dordrecht, pp. 233-246. https://doi.org/10.1007/978-94-011-1566-7_15

Franken, J., BRANDT, B.A., TAI, S.L. \& BAuER, F.F. (2013). Biosynthesis of levan, a bacterial extracellular polysaccharide, in the yeast Saccharomyces cerevisiae. PLoS One 8(10): e77499. https://doi.org/10.1371/journal.pone.0077499

Furze, M.E., Huggett, B.A., Aubrecht, D.M., Stolz, C.D., CARbone, M.S. \& Richardson, A.D. (2019). Whole-tree nonstructural carbohydrate storage and seasonal dynamics in five temperate species. New Phytologist 221(3): 1466-1477. https://doi.org/10.1111/nph.15462

HENDRY, G.A.F. \& WALLACE, R.K. (1993). The origin, distribution and evolutionary significance of fructans. In: SuzukI, M. \& Chatterton, J.N. (eds.): Science and technology of furctans. CRC Press, Boca Raton, pp. 119-140. 
Hincha, D.K., Zuther, E., Hellwege, E.M. \& Heyer, A.G. (2002). Specific effects of fructo- and gluco-oligosaccharides in the preservation of liposomes during drying. Glycobiology 12(2):103-110.

https://doi.org/10.1093/glycob/12.2.103

HinchA, D.K., ZuthER, E. \& HEYER, A.G. (2003). The preservation of liposomes by raffinose family oligosaccharides during drying is mediated by effects on fusion and lipid phase transitions. Biochimica et Biophysica Acta 1612(2): 172177. https://doi.org/10.1016/S0005-2736(03)00116-0

KAWAKAMI, A., SATO, Y. \& YoshidA, M. (2008). Genetic engineering of rice capable of synthesizing fructans and enhancing chilling tolerance. Journal of Experimental Botany 59(4):793-802. https://doi.org/10.1093/jxb/erm367

KeRR, G.P. \& CARTER, J.V. (1990). Tubulin isotypes in rye roots are altered during cold acclimation. Plant Physiology 93: 83-88.

https://doi.org/10.1104/pp.93.1.83

LEWIS, D.H. (1984). Occurrence and distribution of storage carbohydrates in vascular plants. In: LEwIS, D.H. (ed.): Storage Carbohydrates in Vascular Plants. Cambridge University Press, Cambridge, pp. 1-52.

LI, H.J., YANG, AF, ZHANG, X.C., GAO, F. \& ZHANG, J.R. (2007). Improving freezing tolerance of transgenic tobacco expressing sucrose: sucrose 1fructosyltransferase gene from Lactuca sativa. Plant Cell Tissue Organ Culture 89(1): 37-48. https://doi.org/10.1007/s11240-007-9213-8

LiMAMI, A. \& FIALA, V. (1993). Fructan polymerization and depolymerization during the growth of chicory (Cichorium intybus L.) plants. In: Fuchs, A. (ed.): Inulin and inulin-containing crops. Elsevier Science, pp. 191-197. https://doi.org/10.1016/B978-0-444-89369-7.50031-2

LiU, W., Su, J., LI, S., LANG, X. \& HuANG, X. (2018). Non-structural carbohydrates regulated by season and species in the subtropical monsoon broad-leaved evergreen forest of Yunnan Province, China. Nature-Scientific reports 8: 1083. https://doi.org/10.1038/s41598-018-19271-8

Livingston, D.P. \& Henson, C.A. (1998). Apoplastic sugars, fructans, fructan exohydrolase, and invertase in winter oat: responses to second-phase cold hardening. Plant Physiology 116(1): 403-408. https://doi.org/10.1104/pp.116.1.403

MAAS, W.S.G. \& CRAIGIE, J.S. (1964). Examination of some soluble constituents of Sphagnum gametophytes. Canadian Journal of Botany 42: 805-813. https://doi.org/10.1139/b64-072

MARSCHALL, M. (2010). Photosynthetic responses, carbohydrate composition and invertase activity in fructan accumulating bryophytes (Porella platyphylla and Sphagnum flexuosum) under different environmental conditions (carbohydrate treatments, dark starvation, low temperature, desiccation). Acta Biologica Hungarica 61: 120-129. https://doi.org/10.1556/ABiol.61.2010.Suppl.12

Marschall, M., Proctor, M.C.F. \& Smirnoff, N. (1998). Carbohydrate composition and invertase activity of the leafy liverwort Porella platyphylla. New Phytologist 138: 343-353. https://doi.org/10.1046/j.1469-8137.1998.00102.x

Peshev, D., Vergauwen, R., Moglia, A, Hideg, É. \& Van den Ende, W. (2013). Towards understanding vacuolar antioxidant mechanisms: a role for fructans? Journal of Experimental Botany 64(4): 1025-1038. https://doi.org/10.1093/jxb/ers377 
Pilon-Smits, E.A.H., Terry, N., Sears, T. \& Dun, K. (1999). Enhanced drought resistance in fructan-producing sugar beet. Plant Physiology and Biochemistry 37(4): 313-317. https://doi.org/10.1016/S0981-9428(99)80030-8

Pilon-Smits, E.A.H., Ebskamp, M., Paul, M.J., Jeuken, M., Weisbeek, P.J. \& Smeekens, S. (1995). Improved performance of transgenic fructan-accumulating tobacco under drought stress. Plant Physiology 107(1):125-130.

https://doi.org/10.1104/pp.107.1.125

Pollock, C.J. (1986). Tansley review No. 5 Fructans and the metabolism of sucrose in vascular plants. New Phytologist 104: 1-24.

https://doi.org/10.1111/j.1469-8137.1986.tb00629.x

Pollock, C.J. \& JonES, T. (1979). Seasonal patterns of fructan metabolism in forage grasses. New Phytologist 83(1): 9-15.

https://doi.org/10.1111/j.1469-8137.1979.tb00720.x

PonTis, H.G. (1989). Fructans and cold stress. Journal of Plant Physiology 134(2): 148-150. https://doi.org/10.1016/S0176-1617(89)80047-1

Puebla, A.F., SAlerno, G.L. \& Pontis, H.G. (1997). Fructan metabolism in two species of Bromus subjected to chilling and water stress. New Phytologist 136(1): 123129. https://doi.org/10.1111/j.1469-8137.1997.tb04738.x

SANADA, Y., TAKAI, T. \& YAMADA, T. (2007). Ecotypic variation of water-soluble carbohydrate concentration and winter hardiness in cocksfoot (Dactylis glomerata L.). Euphitica 153: 267-280.

https://doi.org/10.1007/s10681-006-9262-9

Sissons, M.J. \& FELLOWS, C.M. (2014). Sensory, technological, and health aspects of adding fiber to wheat-based pasta. In: WATSON, R.R., PREEDY, V.R. \& ZIBADI, S. (eds.): Wheat and rice in disease prevention and health. Academic Press. pp. 211-226. https://doi.org/10.1016/B978-0-12-401716-0.00017-9

SMOUTER, H. \& Simpson, R.J. (1991). Fructan metabloism in leaves of Lolium rigidum Gaudin. I. Synthesis of fructan. New Phytologist 119: 509-516. https://doi.org/10.1111/j.1469-8137.1991.tb01042.x

Soja, G., Haunold, E. \& PrazniK, W. (1989). Translocation of ${ }^{14} \mathrm{C}$-assimilates in Jerusalem Artichoke (Helianthus tuberosus L.) Journal of Plant Physiology 134(2): 218-223. https://doi.org/10.1016/S0176-1617(89)80059-8

Suleiman, A.A.A., Bacon, J., Christie, A. \& Lewis, D.H. (1979). The carbohydrates of the leafy liverwort, Plagiochila asplenioides (L.) Dum. New Phytologist 82: 439448. https://doi.org/10.1111/j.1469-8137.1979.tb02670.x

SuzUKI, M. (1989). Fructans in forage grasses with varying degrees of coldhardiness. Journal of Plant Physiology 134(2): 224-231. https://doi.org/10.1016/S0176-1617(89)80060-4

Suzuki, M. \& ChATTERTon, N.J. (1993). Science and Technology of Fructans. CRC Press, $384 \mathrm{pp}$.

VAlluRu, R. \& VAN DEN ENDE, W. (2008). Plant fructans in stress environments: emerging concepts and future prospects. Journal of Experimental Botany 59(11): 2905-2916. https://doi.org/10.1093/jxb/ern164

Van den Ende, W., Mintiens, A., Speelers, H., Onuoha, A.A., \& Laere, A.V. (1996). The metabolism of fructans in roots of Cichorium intybus during growth, storage and forcing. New Phytologist 132: 555-563.

https://doi.org/10.1111/j.1469-8137.1996.tb01874.x 
Van den Ende, W., Yoshida, M., Clerens, S., Vergauwen, R. \& Kawakami, A. (2005). Cloning, characterization and functional analysis of novel 6-kestose exohydrolases (6-KEHs) from wheat (Triticum aestivum L.) New Phytologist 166: 917-932. https://doi.org/10.1111/j.1469-8137.2005.01394.x

Van den Ende, W., Coopman, M., Clerens, S., Vergauwen, R., Le Roy, K., Lammens, W. \& VAN LAERE, A. (2011). Unexpected presence of graminan- and levan-type fructans in the evergreen frost-hardy eudicot Pachysandra terminalis (Buxaceae): purification, cloning, and functional analysis of a 6-SST/6-SFT enzyme. Plant Physiology 155(1): 603-614. https://doi.org/10.1104/pp.110.162222

VAn Der Meer, I.M., EbSKamp, M.J.M., VisSer, R.G.F., WeisbeeK, P.J. \& SmeeKens, S.C.M. (1994). Fructan as a new carbohydrate sink in transgenic potato plants. The Plant Cell 6(4): 561-570. https://doi.org/10.1105/tpc.6.4.561

Vereyken, I.J., Chupin, V., Demel, R.A., Smeerens, S.C. \& De KrujfF, B. (2001). Fructans insert between the headgroups of phospholipids. Biochimica et Biophysica Acta 1510(1-2): 307-320. https://doi.org/10.1016/S0005-2736(00)00363-1

Vijn, I. \& SMEEKEnS, S. (1999). Fructan: more than a reserve carbohydrate? Plant Physiology 120: 351-359. https://doi.org/10.1104/pp.120.2.351

Volaire, F. Thomas, H. \& Lelievre, F. (1998). Survival and recovery of perennial forage grasses under prolonged Mediterranean drought. New Phytologist 140: 439-449. https://doi.org/10.1111/j.1469-8137.1998.00287.x

WAGNER, W. \& WiEMKEN, A. (1986). Properties and subcellular localization of fructan hydrolase in the leaves of barley (Hordeum vulgare L. cv Gerbel). Journal of Plant Physiology 123(5): 429-439. https://doi.org/10.1016/S0176-1617(86)80227-9

WAite, R. \& BoyD, J. (1953). The water-soluble carbohydrates of grasses. I. Changes occurring during the normal life-cycle. Journal of the Science of Food and Agriculture 4(4): 197-204. https://doi.org/10.1002/jsfa.2740040408

WiSE, C.S., Dimler, R.I., DAvis, H.A. \& RisT, C.E. (1955). Determination of easily hydrolysable fructose units in dextran preparations. Analytical Chemistry 27: 33-36. https://doi.org/10.1021/ac60097a011

Yамамото, S. \& Mino, Y. (1985). Partial purification and properties of phleinase induced in stem base of orchardgrass after defoliation. Plant Physiology 78(3): 591-595. https://doi.org/10.1104/pp.78.3.591

Yoshida, M., KaWakami, A., Van den Ende, W., Shiomi, N., Benkeblia, N. \& Onodera, S. (2007). Graminan metabolism in cereals: wheat as a model system. Recent Advances in Fructooligosaccharides Research. Research Signpost, Kerala, pp. 201-212.

YoshidA, M. \& TAMURA, K. (2011). Research of fructan in wheat and temperate forgae grasses in Japan. Japan Agricultural Research Quarterly 45(1): 9-14. https://doi.org/10.6090/jarq.45.9

(submitted: 10.12.2019, accepted: 28.12.2019) 